\title{
Challenges in Determining the Employment Generated by Climate-Change Policies
}

\author{
Jabran Kayani*
}

School of Aerospace Engineering, Kingston University, KT1 $1 L Q$

\begin{abstract}
In the existing economic crisis and the impending global catastrophic effects of the climate change renewable energy technology provide an opportunity to harness the environmentally abundant energy sources to spur economic growth. This paper examines the global effects of climate change and the resulting policies to mitigate the crises. The evolution of the climate change policies into its current form and how they have replaced employment in the conventional energy sector. It analyses several models which shed a favourable light on increased spending in renewable energy sources and why certain industries consider it a threat to the whole economy.
\end{abstract}

Keywords: Climate change policy, employment, energy policy, GHG, renewable energy source.

\section{INTRODUCTION}

The evidence of climate change is irrefutable. The effects of the emissions of GHG's in to the atmosphere are global. Climate change poses a global catastrophe and ignoring or delaying any remedial measures can lead to irreversible global social, environmental and economic problems. The current level of $\mathrm{CO}_{2}$ in the atmosphere is around 396 parts per million (ppm) compared to levels before the industrialization $(280 \mathrm{ppm})$. There is evidence that the world has warmed up by $0.5^{\circ} \mathrm{C}$ due to these emissions and will further warm up by $2^{\circ} \mathrm{C}$ by 2035 if the GHG emissions accelerate because of increased investments in transport and infrastructure around the world. According to the worst case scenario economic models used by the Stern review (2007) the cost of not mitigating the climate change would be around $20 \%$ of the world's GDP per annum while only $1 \%$ of the world's GDP can be set aside for measures to alleviate the worst effects of climate change [1]. The EU policy for climate change aims to reduce GHG emissions by 2050 to $80 \%$ below the 1990 level. The current global economic crises and the austerity measures adopted by the European countries have made it difficult for the public to accept new energy policies, a point well demonstrated by the European Parliament's rejection of the back-load emissions rights proposal in 2013. Given the predicament of climate change a robust policy engaging different technological mixes are needed for post 2020 as Strategic Energy Technology Plan (SET Plan) expires in 2020 [2-4].

\section{LITERATURE REVIEW}

Renewable Energy (RE) provides an opportunity to mitigate the effects of climate change and provide energy

\footnotetext{
*Address correspondence to this author at the School of Aerospace Engineering, Kingston University, KT1 1LQ. River House, 53-57 High Street, Kingston upon Thames, Surrey KT1 1LQ; Tel: 0061 406601671;

E-mail: jabrank@hotmail.com
}

security given the highly volatile geo-political scenario. Energy from RE sources is currently expensive compared to other traditional energy sources and the RES industry is heavily subsidized. Technological advances in RES and persistent climate control policies would inducean environment for investment which would naturally encourage economic activity and job creation [5].

There are two methods to investigate the effect of job creation by RES.

- Input and output method (I-O method)

- Analytical method

\subsection{Input and Output Method}

This method is used to measure the effect of one sector on the secondary or tertiary sectors of the economy. There are three main effects that a sector has on an economy. The requirements for material and services that will be directly utilized in the main sector are the direct effect. The raw material requirement impact on the material industry by the demands of the primary sector is the indirect effect. And the tertiary effect created by the very existence of an industry on the service industry and goods is the induced effect $[6,7]$.

\subsection{Analytical Methods}

Analytical methods are very limited in their applications as they cannot determine indirect job creation and require surveys to be conducted.

The literature is littered with confusing and ambiguous terminologies to measure job creation in the RES sector. "Person-year per MW installed, Jobs per annual MW installed, manufacturing jobs per MW, jobs per cumulative MW installed" [8] People permanently employed in the operation and maintenance stages are indicated by jobs per MW installed while temporary jobs are indicated by personyear per MW. Fig. (1) show the employment ratio of a specific area but this example can be used for other areas as 


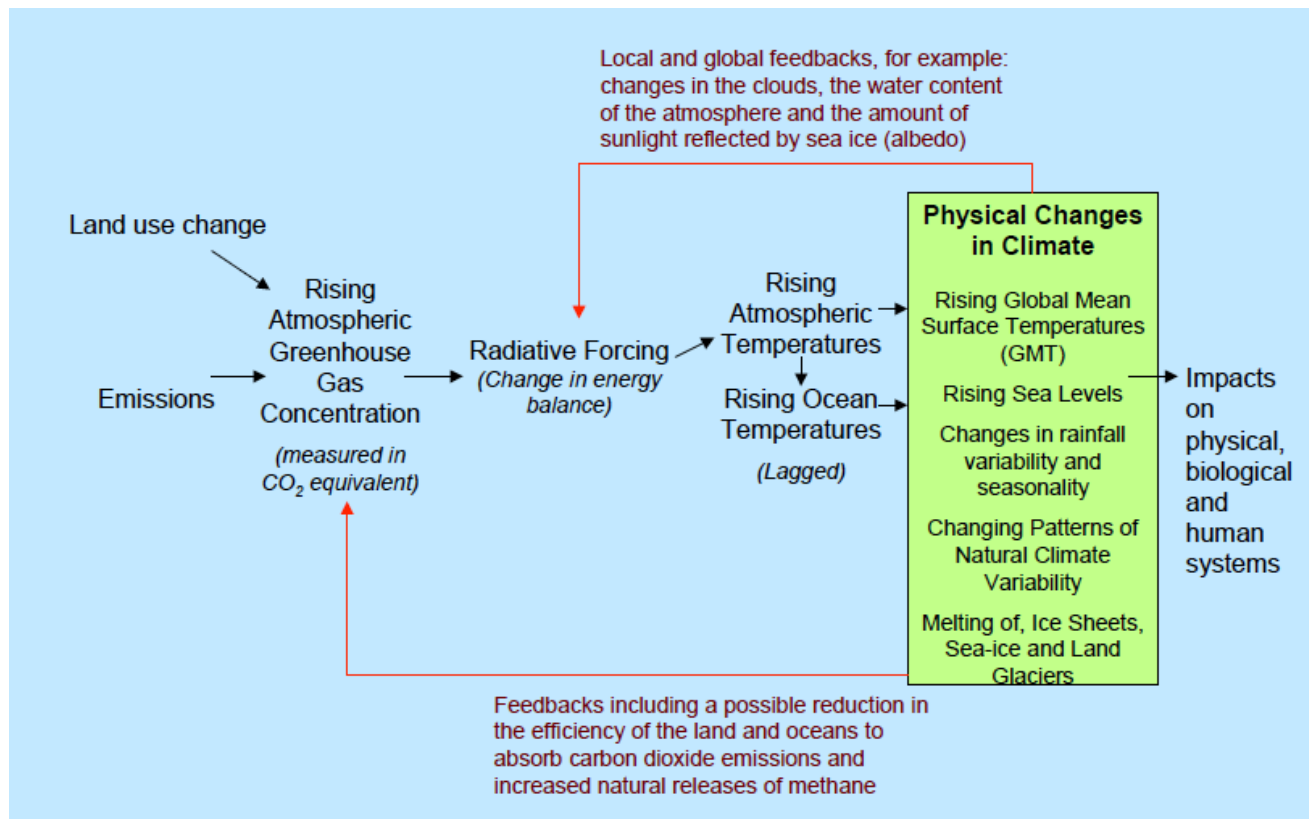

Fig. (1). The connection between climate change and GHG emission, from (Stern, 2007).

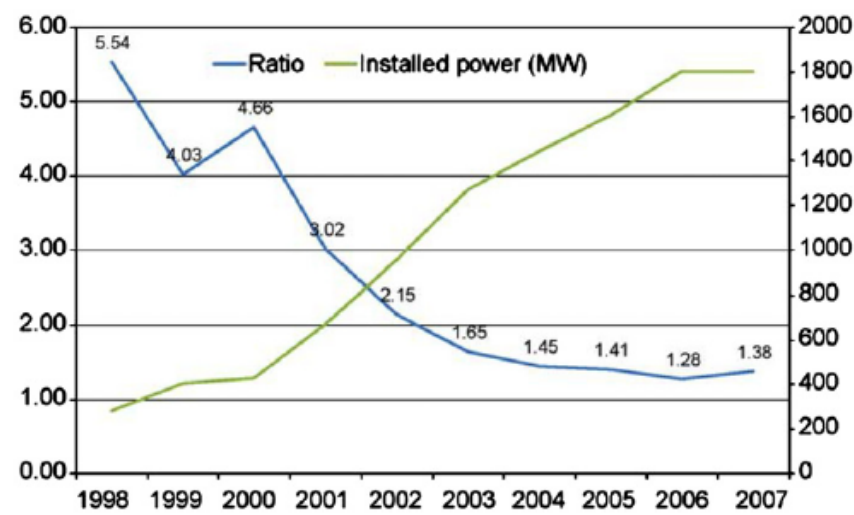

Fig. (2). Employment ratio in Aragon, Spain, from (Lambert \& Silva, 2012).

well. From Fig. (2) the employment ratio decreases as the connected power increases during the course of time, apart from the spike at year 2000 where Spain introduced the Plan for the Promotion of Renewable Energy. Any new policy which promotes the RES will have a positive impact on the job creation in the short term due to the creation of construction and installation jobs and then subsiding as O\&M personals are required [8].
Compared to natural gas plants RES plants create between 1.7 to 14.7 times more jobs and around four times more than the coal powered electricity plants for every MW installed. The inherent ability of renewable energy sector to employ more people per MW than conventional energy sector has gained a lot of attention and stirred a lot of debate in policy making. As private entities are more focused on the job creation by a project, policy makers are more concerned about the future direction of a specific policy path, its effects on the wider economy and any unforeseeable spill overs [9].

According to Frondel, et al., [10] Renewable energy industry is more labour intensive compared to other conventional industries. The increased uptake of employees can be regarded as a good thing but it also means that renewable energy is less efficient per worker with lower productivity. Michaels \& Murphy [11] disagree with the increased number of labour in the energy sector and argue that fewer workers would cost less thereby decreasing the cost of the energy and increasing the economy's output potential. They further argue that job destruction of conventional energy sources are completely omitted when considering job creation by RES. They point out that the service industry related to the conventional energy industry would suffer drastically and energy intensive industries would be burdened with higher en-

\begin{tabular}{ll}
\hline Country & Job ratio (direct jobs/MW installed) \\
\hline Belgium & 6.97 \\
Denmark & 5.44 \\
Austria & 0.76 \\
Czech Republic & 0.86 \\
Spain & 1.35 \\
Germany & 1.71 \\
France & 2.44 \\
\hline
\end{tabular}

Fig. (3). Job ratios in the wind industry in Europe, from (Lambert \& Silva, 2012). 
ergy cost. Higher cost of electricity will result in higher cost of commodities and less consumption by the consumer which would result in slow economic activity, if not economic stagnation, and potential job loss in the production industry [12]. Any diversion of funds to the renewable energy sector would mean that the budget for other industries and public services would have to be curtailed. This trend will reduce the economic turnover, taxation and employment in the other sectors [13]. Lesser [12] also argues that as the renewable energy sector is highly subsidized, the economist and policy makers are will-fully ignorant of its secondary effects on the job market and regards it as a "free-lunch economics".

According to the research conducted on behalf of European Commission DG Energy and Transport [14] a net increase in employment would occur in Europe if RES favourable policies and technologies are adopted. The development of the RES industry has already added $0.6 \%$ to the European GDP and employment Fig. (3). The report acknowledges that high cost of renewable energy and diverted funds from conventional energy sources portray very small net figures. The positive effects are due to growing number of RES installations and the export industry. In order for the policies to have the intended long term effect the European RES industry must retain and improve their competitive advantage and reduce the cost. International collaboration and market penetration especially in the middle-east would maintain the trajectory of the domestic European RES policy by increasing GDP, jobs and a favourable balance of sheets. This path would aid in abating GHG emissions world-wide, the primary motive for the climate change movement, and help in much needed energy security due to reduced imports of fossil fuels. (European Commission DG Energy and Transport, 2009).

\section{ENERGY SECURITY}

Blum and Legey (2012) attempt to conceptualise energy security in terms of welfare and sustainable development by defining welfare of an economy by ethical distribution of its energy sources and the environmental effects from the consumption of it. In order to achieve welfare of energy, the economy must guarantee the availability of energy sources to be inexpensive and environmentally friendly. Such guarantees and preservation of these guarantees relates to the energy security of the economy [15].

$36 \%$ of natural gas consumption in 2010 is produced by Europe itself. Total Primary Energy Supply (TPES) in 2008 was about $85 \%$, Russia leading as the main exporter of energy to Europe in 2008 with $32 \%$ of natural gas, $29 \%$ crude oil and $24 \%$ coal [16].

The existing infrastructure to import energy from Russia is outdated and further investment would be necessary to modernize it. Recent political crises in Ukraine would increase uncertainty in energy supply through its territories, leading to short-term supply shortfalls. Any increase in Russian domestic demand due to industrialization and economic development would divert some of its energy exports for domestic consumption resulting in scare and expensive energy imports for Europe. As observed in the not so distant past Russia used natural gas for political leverage in Western
Europe [17]. Any move towards natural gas dependency would be a cause of concern. Most of the natural gas for Europe is imported from North Africa, Middle East and Norway. To counter the unpredictable nature of geo-politics, storage facilities have to be upgraded [15].

For indigenous production shale gas can be an alternative to energy dependency but the environmental risks involved in extraction are great. Highly carcinogenic chemicals are required in the extraction processes and extremely high water usage and disposal of produced water are the chief environmental concerns. Shale gas requires high land usage. Shale gas can severely restrict the range of opportunities available for individuals. There are reports of methane contamination in ground water tables [18, 19]. There has to be an outright switch in environmental policy to warrant any exploration of shale gas.

\section{PROMOTION OF RES}

Germany adheres strictly to its emission targets and has surpassed in 2007 the Kyoto GHG emission reduction of $21 \%$ for 2012 . The German policy makers were contemplating at least $20 \%$ energy from RES by 2020 but due to the technological innovation and growth spurred by the climate policy, the target was raised to $30 \%$ in 2009 and later increased to $35 \%$ in 2010 as specified by the German federal Government Energy concept. Such favourable outcomes are the result of the policies adapted by the Government which triggered technological innovation and new patent. In 2010 at least 370,000 people were employed in RES industry [20].

The GHG reduction and energy saving was also achieved by stringent policies for the construction industry. The regulation for energy consumption in new buildings by 2012 has seen saving equivalent to $80 \%$ compared to the costs of 1984. From 2006 to 2009 the government subsidised the $\mathrm{CO}_{2}$ building renewal scheme by $€ 6$ billion. This in turn prompted $€ 30$ billion worth of investment from the private sector and generated 290,000 jobs. The government in its 2010 energy concept proposes that all new buildings by 2020 should be "climate neutral" and demand for heating reduce by $20 \%$ and "all buildings should be almost entirely climateneutral" by 2050. Due to the recent nuclear disaster in Japan the Federal Government has increased its grants, with tax break, to eco-friendly enterprises to $€ 1.5$ billion per annum. This economic stimulus would further increase the economic activity prompting European and international investments $[18,19]$.

Spain enjoys a global presence in solar and wind technology. Spain has developed considerably in the renewable energy sector and like Germany, Spain is expected to exceed the targets for $20 \%$ for 2020 coming from RES by more than $20 \%$. The RES industry has created approximately 200,000 jobs in Spain and with the construction of a 1,500 MW wind farm in Romania by Iberdrola, a Spanish company, it would certainly have a direct, indirect and induced effect on the European job market. But Spain fails miserably when it comes to GHG emissions control according to the Kyoto protocol as its emissions between 1990 and 2007 exceed 52.5\%. This irregularity can be attributed to the wider economic benefits of adopting RES technologies as opposed to the benefits of GHG emissions control in the climate policy $[18,19]$. 
UK's planned GHG emission reduction for 2020 was around $26 \%$ and for 2050 was $80 \%$. But due to effective climate change policies and growth in economy due to induced investment the target was increased to $34 \%$ by $2020[18,19]$. UK energy efficiency policy also contributes in the success of GHG emission control and development of RES. According to Low Carbon Construction Innovation and Growth Team's (IGT) proposal the environmental impacts would be evaluated at the conceptual design stage of the building to better inform and implement strategies to reduce the energy and carbon emission of the project [21].

\section{DISCUSSION}

A stimulus package is necessary for any economic growth. Investment in renewable energy in Europe would induce an environment of economic growth, job creation and climate awareness. Construction of renewable energy power plants, building zero carbon building construction and retrofitting of existing building to make them more energy efficient, improving the power grid, applying cogeneration of electricity and heat etc., will induce job creation in the primary industry as well as the service industries. According to Jaeger, et al., [16] the economic model for future growth with climate change policies and more reliance on RES would result in $25 \%$ increase in investment compared to business as usual BAU model with the emissions target at $30 \%$. The financial crisis of 2007-2008 has reduced GDP of Europe by $4 \%$. Following a BAU policy Europe would see high average unemployment and social inequalities. The prospect of creating a low carbon economy can salvage Europe from its dire economic predicament by raising investments resulting in growth and job creation. In the New Growth Path for Europe (2011) a study commissioned by the German Federal ministry for the environment proposes that the path for green growth shouldn't be just looked at in terms of renewable energy plants construction or the amount of investment in them. Rather as a shared vision for sustainable development for the future by improving quality of life collectively and increasing investments in communal wellbeing like housing, education, hospitals, entertainment.

Fig. (4) shows two emissions scenarios that can spur growth and reduce unemployment. The target of achieving $20 \%$ emission reduction by 2020 is not only achievable but easily surpass-able by many European countries. The assumption in the study isonly the reduction of emission by

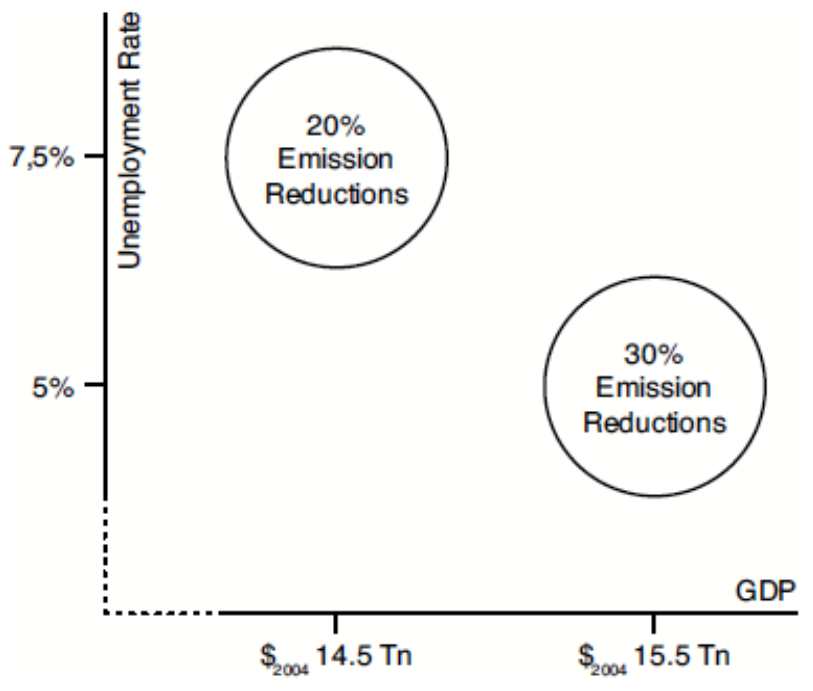

Fig. (4). Two emissions scenario, from (Jaeger, et al., 2011).

$30 \%$ of 1990 level and no new international climate change agreement after the Copenhagen Agreement of 2009. Table 1 sum up the benefit of pursuing this policy. The European economy increases by $0.6 \%$ per annum compared to the BAU model. Increase in investment by $4 \%$ of GDP in 2020 and an increase of 842 billion in GDP, generating additional 6 million employment opportunities. This study might portray a very optimistic picture but recent industrial developments in Europe indicate that GDP growth can also be achieved by emission reduction rather than increased activity of polluting industry as conventionally believed. To achieve such reductions huge investments have to be made to transform the energy intensive industries into a renewed sustainable and energy efficient built environment. Another optimistic growth rate that the study mentions is the GDP growth above the BAU of $2.2 \%$. Considering precrises growth rate of many European countries it is evident that their GDP growth rate was well above $2.2 \%$. Another factor fuelling this optimism is the productivity gains through learning-bydoing encouraged by investments particularly in the new material technology for construction and RES [15]

Investment in RES will see a broader growth in different sectors of the economy such as construction, agriculture, industry, services and power.

Table 1. Raising the emission bar from $20 \%$ to $30 \%$, from (Jaeger, et al., 2011).

\begin{tabular}{|l|r|r|r} 
& $\begin{array}{r}\text { Green } \\
\text { Growth }\end{array}$ & $\begin{array}{r}\text { Business } \\
\text { as Usual }\end{array}$ & \multicolumn{1}{c|}{$\Delta$} \\
\hline GDP in 2020 (billion $\$_{2004}$ ) & 15421 & 14579 & $5.77 \%$ \\
GDP growth-rate 2010-2020 & $2.8 \%$ & $2.2 \%$ & $0.6 p p$ \\
Unemployment rate in 2020 & $5.3 \%$ & $7.6 \%$ & $-2.3 p p$ \\
Number of unemployed (millions) & 13.4 & 19.4 & $-30.9 \%$ \\
Investment in 2020 (share of GDP) & $22.4 \%$ & $18.4 \%$ & $4.0 p p$ \\
Investment in 2020 (billion $\$_{2004}$ ) & 3457 & 2685 & $28.8 \%$ \\
Emissions $\left(\mathrm{Mt}\right.$ of $\left.\mathrm{CO}_{2} \mathrm{e}\right)$ & 3927 & 4414 & $-11.0 \%$ \\
Carbon Price $\left(€ / \mathrm{t} \mathrm{CO}_{2}\right.$ ) & 32.19 & 19.47 & $65.3 \%$ \\
\hline
\end{tabular}

$\Delta$ : Difference $20 \%$ vs. $30 \%$ either as percentage of $20 \%$ value or as difference in percentage points ( $p p$ ). 


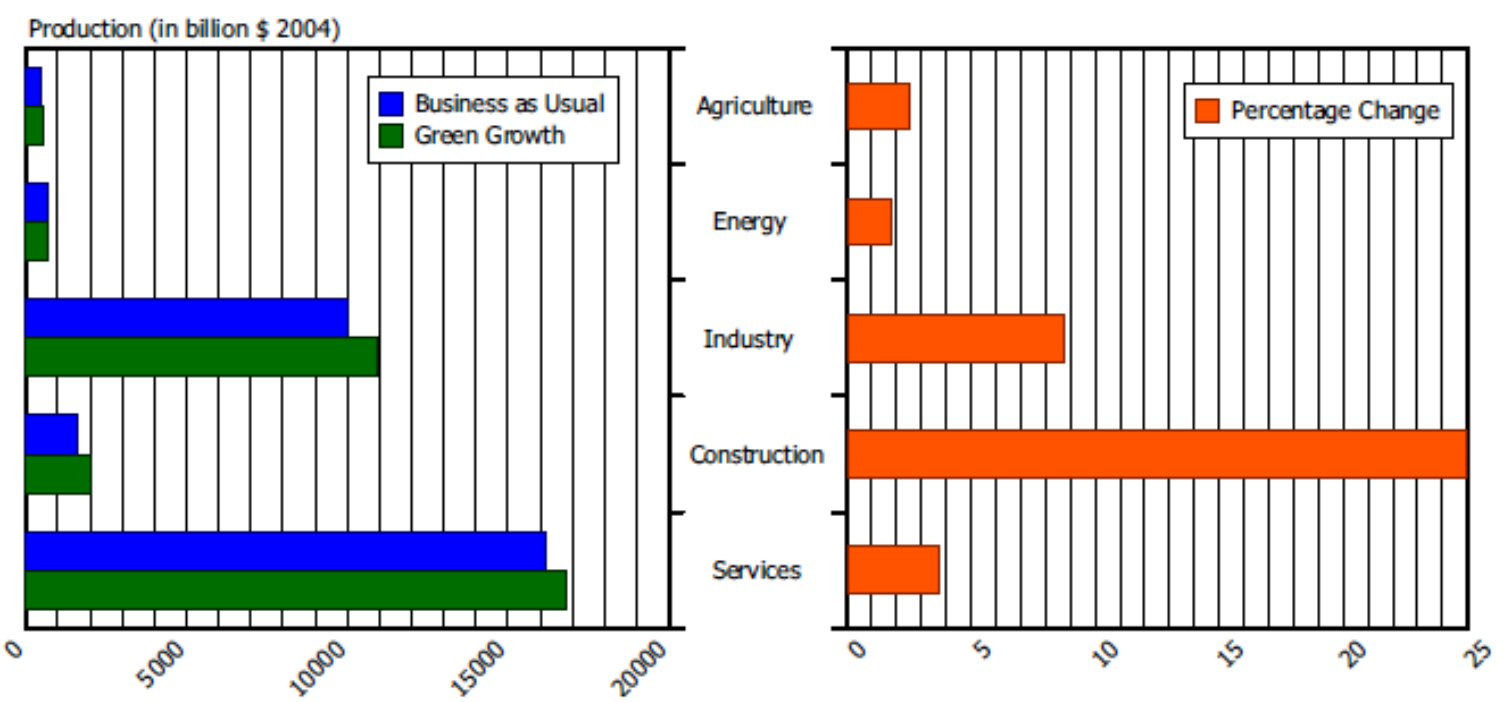

Fig. (5). Sector-wise production EUR27, from (Jaeger, et al., 2011).

According to Fig. (5) the largest percentage gain is seen in the industry sector which would entail retrofitting of existing building for energy efficiency and compliance to new industry standards for new building. Such activity would naturally induce development in cost effective material technology and job creation. Construction industry is inherently one of the most polluting and this emission can be easily offset by reduced emissions as a result of energy efficiency innew and retro-fitted buildings. According to one estimate, low carbon technology market would exceed $\$ 500$ billion dollar by 2050[19]. Another research conducted by Shell Springboard [20] puts this figure as high as $\$ 2$ trillion per annum by 2050 with cumulative growth of $\$ 1$ trillion in five years globally. This economic activity would naturally incur job growth, an estimation of 25 million people employed directly or indirectly by 2050 in low-carbon technology market [1].

\subsection{Financial Sector}

Apart from the primary and the secondary sectors of the economies the tertiary industries would play a vital role in raising the money to realize climate change and renewable energy policies. Financial institutions would assist in setting up funds for start-up, small and medium businesses and large corporations. Companies require funds to improve their current infrastructure and conform to legislations. New research and marketing companies are also developing to assist and tap into the boom of low-carbon technology investment. The financial sector can benefit from the development and formalising of carbon trading markets with trading worth $\$ 10$ billion per year worldwide [21].

Due to risk involved in unpredictable weather conditions the insurance sector will be braced for higher risk and great opportunities.

\section{CONCLUSION}

Industries with high carbon activities would suffer, while marked growth and development would be seen in efficient and green technologies. Huge investments would be needed to accomplish a paradigm shift towards RES and ecofriendly processes. It will create new markets to service the emerging industries and entrepreneurial ambitions would see technological advances in systems and material. Due to strong governmental policy on climate change and high fossil fuel prices in 2005 the renewable energy sector grew by $25 \%$. The total market value of solar increased to $\$ 27$ billion and biofuels to $\$ 15$ billion in 2006. To maintain this growth, effective long term policies by the government are needed, focusing on technological pathways for energy efficient processes, materials and machinery. The governmental policies cannot be viewed as an externality and subject to market whips and consideration. It is a driver that dictates the future pathway, governs and controls the market imperfection. It motivates industries, individual and private enterprises to evolve and to effectively face current challenges. The IEA's Energy Technology Perspectives report estimates that investments in renewable energy technologies would be over $\$ 13$ trillion by 2050 with the assumptions that emissions be brought down to 2005's level. The paramount question is whether Europe can cope with the tri challenge of reducing GHG emissions, increasing economic activity and job creation? [1]. Even with a conservative outlook on the economic front, climate change policy should be strictly adhered to. Otherwise the consequences of global warming would be drastic and beyond human experience. Any steps to mitigate the crisis would be fruitless and total economic chaos would ensue.

\section{CONFLICT OF INTEREST}

The authors confirm that this article content has no conflict of interest.

\section{ACKNOWLEDGEMENTS}

Declared none.

\section{REFERENCES}

[1] N. Stern, "Review: The Economics of Climate Change," Cambridge: Cambridge University Press, 2007. 
[2] S. Ruester, S. Schwenen, M. Finger, and J. M. Glachant, "A post2020 EU energy technology policy: Revisiting the strategic energy technology plan," Energy Policy, vol. 66, pp. 209-217, 2014.

[3] M. Kanellakis, G. Martinopoulos, and T. Zachariadis, "European energy policy-A review," Energy Policy, vol. 62, pp. 1020-1030, 2013.

[4] U. Lehr, C. Lutz, and D. Edler, "Green jobs? Economic impacts of renewable energy in Germany," Energy Policy, vol. 47, pp. 358364, 2012.

[5] R. J. Lambert, and P. P. Silva, "The challenges of determining the employment effects of renewable energy," Renewable and Sustainable Energy Reviews, vol. 16, pp. 4667-4674, 2012.

[6] H. G. Huntington, “Creating Jobs With 'Green' Power Sources," Stanford: USAEE Dialogue, vol.17, no.1. 2009.

[7] F. Cabeza, L. Rincóna, V. Vilariñob, G. Péreza, and A. Castell, "Life cycle assessment (LCA) and life cycle energy analys is (LCEA) of buildings and the building sector: A review," Renewable and Sustainable Energy Reviews, vol. 29, pp. 394-416, 2014.

[8] E. Llera, S. Scarpellini, A. Aranda, and I. Zabalza, "Forecasting job creation from renewable energy deployment through a value-chain approach," Renewable and Sustainable Energy Reviews, vol. 21, pp. 262-271, 2013.

[9] M. Frondel, N. Ritter, M. Schmidt, and C. Vance, "Economic impacts from the promotion of renewable energy technologies: The German experience," Energy Policy, vol. 38, pp. 4048-4056, 2010.

[10] R. Michaels, and R. P. Murphy, "REEN JOBS: Fact or Fiction,"?, InstGiture For Energy Research., 2009.

[11] J. A. Lesser, "Renewable Energy and the Fallacy of 'Green' Jobs," The Electricity Journal, vol.23, no.7, pp. 45-53, 2010.
[12] Hughes, "The myth of green jobs, " London: The Global Warming Policy Foundation, 2011.

[13] European Commission DG Energy and Transport, "The impact of renewable energy policy on economic growth and employment in the European Union," s.1.: s.n., 2009.

[14] H. Blum, and L. F. Legey, "The challenging economics of energy security: Ensuring energy benefits in support to sustainable development," Energy Economics, vol.34, pp. 1982-1989, 2012.

[15] C. C. Jaeger, L. Paroussos, D. Mangalagiu, R. Kupers, A. Mandel and J. D. Tàbara, "A new growth path for Europe - Generating prosperity andjobs in the low-carbon economy, Potsdam: European Climate Forum, 2011.

[16] L. Sagen, and M. Tsygankova, "Russian Natural Gas Exports to Europe: Effects of Russian Gas Market Reforms and the Rising Market Power of Gazprom," Berlin: DIW-Diskussionspapiere, 2006.

[17] I. D. Melo-Martín, J. Hays, and M. L. Finkel, "The role of ethics in shale gas policies," Science of the Total Environment, vol. 470-471, pp. 1114-1119, 2014.

[18] M., Jänicke, "Dynamic governance of clean-energy markets: how technical innovation could accelerate climate policies"' Journal of Cleaner Production, vol. 22, pp. 50-59, 2012.

[19] A. Moncaster, and K. Symons, "A method and tool for "cradle to grave' embodied carbon and energy impacts of UK buildings in compliance with the new TC350 standards," Energy and Buildings, vol. 66, pp. 514-523, 2013.

[20] Springboard, "The Business Opportunities for SMEs in tackling the causes of climate change, s.1.: Vivid Economics, 2006.

[21] World Bank, "State and Trends of the Carbon Market, " Washinton, DC: World Bank, 2006.

\footnotetext{
Received: May 28, 2015

Revised: July 14, 2015

Accepted: August 10, 2015

(C) Jabran Kayani; Licensee Bentham Open.

This is an open access article licensed under the terms of the (https:/creativecommons.org/licenses/by/4.0/legalcode), which permits unrestricted, non-
} commercial use, distribution and reproduction in any medium, provided the work is properly cited. 